\title{
Efficacy of Oral Rehabilitation Therapy in Terms of Neonatal Outcomes in Preterm Infants
}

\author{
Sang Hoon Chun ${ }^{1}$, Woo-Jin Jeong ${ }^{2}$, and Tae-Jung Sung ${ }^{1}$ \\ ${ }^{1}$ Department of Pediatrics and ${ }^{2}$ Occupational Therapy Team, Department of Rehabilitation Medicine, Hallym University Kangnam \\ Sacred Heart Hospital, Hallym University College of Medicine, Seoul, Korea
}

\section{ABSTRACT}

Purpose: To evaluate the efficacy of oral rehabilitation therapy (ORT) in terms of prematurity-associated morbidities in preterm infants born before a gestational age of 33 weeks.

Methods: This was a single-institution retrospective case-control study including 78 high-risk preterm infants born between January 2015 and December 2016, who were administered with ORT for at least 15 minutes, 2 to 5 times/week by an occupational therapist. Various factors associated with feeding progression and neonatal morbidities were compared between the two groups.

Results: Seventy-eight subjects, of whom 39 were cases and 39 controls, were included

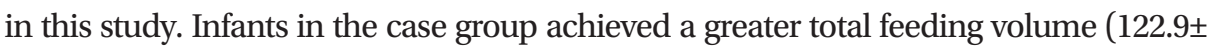
$85.3 \mathrm{~mL}$ vs. $48.9 \pm 25.7 \mathrm{~mL}, P<0.001)$, i.e., 8 times/day with oral feeding only, and showed significantly higher body weight $(1,852.1 \pm 303.3 \mathrm{~g} v \mathrm{vs} .1,592.3 \pm 444.1 \mathrm{~g}, P=0.003)$ than those in the control group with complete oral feeding day. The duration from the first day of oral feeding to full enteral feeding, i.e., $150 \mathrm{~mL}$ /day, was significantly shorter in the cases than that in the controls ( $15.4 \pm 1.4$ days vs. $23.1 \pm 1.8$ days, $P=0.004)$. The body weight at discharge was higher in the cases than that in the controls $(3,102.6 \pm 619.3 \mathrm{~g}$ vs. $2,744.6 \pm$ $436.8 \mathrm{~g}, P=0.008)$. Moreover, the incidence of late-onset sepsis was lower in the cases than that in the controls ( $12.8 \%$ vs. $25.6 \%, P=0.033)$. Other prematurity-associated morbidities were not different between the two groups.

Conclusion: ORT in preterm infants facilitated the transition process from tube feeding to full oral feeding and reduced the incidence of late-onset sepsis.

Key Words: Treatment outcome; Infant, premature; Bottle feeding

\section{서론}

최근 의료기술의 발달과 신생아학의 발전으로 미숙아들의 예후가 급격히 향상되고 있으며 더 어리고 더 미숙한 신생아들의 생존이 눈에 띄게 증가하고 있다 ${ }^{1)}$. 특히 전체 출생 신생아 중 미숙 아가 차지하는 비율은 2000년 3.8\%, 2007년 5.2\%, 2014년에는 6.7\%로 해마다 증가하고 있으며, 저체중아 $\left(<2.5 \mathrm{~kg}\right.$ ) 비율 역시 2004년 4.1\%에서 2014년에는 $5.7 \%$ 로 계속 늘고 있는 추세이다 ${ }^{2)}$.
Received: 1 October 2018

Revised: 12 November 2019

Accepted: 4 January 2019

Correspondence to: Tae-Jung Sung

Department of Pediatrics, Hallym University Kangnam Sacred Heart Hospital, Hallym University College of Medicine, 1 Singil-ro, Yeongdeungpo-gu, Seoul 07441, Korea

Tel: +82-2-829-5142

Fax: +82-2-829-4469

E-mail: neosung@hallym.or.kr https://orcid.org/0000-0002-5406-5550
Copyright(c)

By Korean Society of Neonatology. All right reserved.

This is an Open-Access article distributed under the terms of the Creative Commons Attribution Non-Commercial License (http://creativecommons.org/licenses/ by-nc/4.0), which permits unrestricted non-commercial use, distribution, and reproduction in any medium, provided the original work is properly cited. 
미숙아들은 생리적인 미숙함으로 인해 위장관 운동과 효소 활동이 저하되어 있고, 빨기-삼키기-호흡의 부조화로 인해 경구수유 능력의 발달이 늦어지고, 기도유지가 힘들거나, 영양 공급이 제한적이 되며 수유 부진(feeding intolerance)도 초래할 수 있다 ${ }^{3}$. 또한, 미성숙할수 록 인공호흡기 치료를 포함한 집중적인 치료와 처치로 인해, 경관수 유에서 구강수유로의 이행이 늦어지게 되고, 장기간의 기관삽관, 산 소공급, 잦은 위관 삽입 등의 침습적인 처치는 뇌 발달에도 영향을 주 게 된다 .

이러한 경구수유지연을 해결하는 방법으로 비 영양성 빨기(nonnutritive sucking)와 구강자극요법 치료가 있다 ${ }^{5-7)}$. 구강 재활치료 (oral rehabilitation therapy, ORT)란 수유 전 실시하는 일종의 구강 마 사지 치료로 구강을 적절하게 자극한 뒤 노리개 젖꼭지 등을 이용하 여 비영양성 빨기를 유도하여 효과적인 빨기-삼키기-호흡하기를 연 습하도록 하는 구강자극 중재법으로 이에 관한 연구가 지속적으로 보고되고 있으나 아직 우리나라 미숙아들을 대상으로 시행한 연구는 많지 않다 ${ }^{8-12}$.

따라서 본 연구의 목적은 신생아중환자실(neonatal intensive care unit, NICU)에 입원한 미숙아들의 조기 경구수유능력 증진을 위한 ORT가 미숙아 단기 예후에 어떤 영향을 끼치는지 알아보고 이를 토 대로 앞으로 ORT를 발전시키는데 필요한 효과적인 임상 적용 자료 를 만들고자 하였다.

\section{대상 및 방법}

본 병원의 경우 2016년 재활의학과에서 아동(신생아 및 미숙아 포 함) 담당 재활치료팀이 신설되어 적극적인 ORT가 시작되었다. 따라 서 2016년 1월부터 12월까지 NICU에 입원한 미숙아 중 ORT를 받은 미숙아(치료군)와 2015년 1월부터 12월까지 NICU에 입원한 미숙아 중 치료를 받은 군과 비슷한 재태 주수와 출생체중을 가진 미숙아(대 조군)를 선정하여 비교하였다. 연구 기간 동안 치료군을 매칭하기 전 2015년에 NICU에 입원했던 미숙아들 중 ORT가 꼭 필요하지 않은 33
주 이상의 미숙아(n=109), NICU 퇴원 전 타 병원으로 전원 간 미숙아 $(n=2)$, 사망한 미숙아 $(n=10)$, 선천성 기형아 $(n=1)$, 인공호흡기(비침 습적인 경우 포함)를 유지하고 있는 경우 $(n=3)$, 의무기록이 부실한 미숙아들 $(\mathrm{n}=1)$ 은 제외하였다. ORT는 NICU에 입원 중인 미숙아 중 수태 후 연령(postconceptional age, PMA)이 최소 32주 이상 되고, 활 력징후가 안정화되고, 경관영양을 공급받고 있는 미숙아를 대상으로 하였으며, ORT 대상자로 선정되면 신생아 재활치료 전담작업치료사 가 NICU를 방문하여 하루 15 분간 주간 최소 2 일에서 최대 5 회, 동일 한 방법으로 동일한 시간대(오후 3-5시 사이)에 진행되었다. ORT 프 로토콜은 Choi 등 ${ }^{13)}$ 과 Fucile 등 $^{14}$ 의 논문을 참고하여 본원의 실정에 맞게 조정하였고(Table 1), 정확한 효과 판단 및 동일한 치료를 제공 하기 위해 한 명의 치료사가 NICU 미숙아를 전담으로 하여 진행하였 다. 만약 치료 중 활력징후가 불안정해지거나 무호흡, 서맥 또는 산소 포화도 저하를 보이는 경우 치료를 즉시 멈추고, 약 1 분 뒤 안정화되 면 다시 진행하였으며, 동일한 증상이 3 번 이상 반복되는 경우는 해 당일의 치료를 중단하였다. 서맥의 정의는 심장 박동수가 $<100$ 회/분 인 경우로 정의하였고 산소포화도 감소는 적절한 자극에도 불구하고 $\leq 80 \%$ 가 1 분간 지속될 때로 정의하였다.

수유와 관련된 인자들은 다음처럼 정의하였다. 처음 구강수유 시 작일은 수유량과 관계없이 최소 3 번 연속 경구수유가 가능한 날로 정 했으며, 완전경구(젖병) 수유일(complete oral feeding day)은 경관수 유 없이 경구수유로만 전환되는 날을 의미하여 본 연구에서는 수유 량과 상관없이 8회/일 모두 경구수유가 가능한 날로 정의하였으며, 이때 총 수유량은 완전경구수유로 전환되는 날 신생아가 하루 동안 섭취한 총 수유량을 의무기록을 이용하여 계산하였다. 또한, 완전장 관 영양공급일(full enteral feeding day)은 경구로만 수유가 가능하며 하루 총 수유량이 $150 \mathrm{~mL} / \mathrm{kg}$ 에 도달한 날로 정의했다. 또한, 완전경 구수유가 가능한 날로부터 완전장관수유가 가능한 날까지의 기간을 확인하여 ORT의 효과를 확인하고자 하였다.

그 밖에 치료받은 군과 치료받지 않는 대조군 사이에 NICU 입원 기 간 중 예후 비교를 위해 미숙아 관련 합병증인 기관지폐형성이상, 미 숙아 망막증, 후기 패혈증, 뇌실내출혈, 뇌백질연화증 발생률을 비교

Table 1. Method of Oral Rehabilitation Therapy ${ }^{13,14)}$

\begin{tabular}{|c|c|c|c|}
\hline Site & Stimulation method & Duration (min) & Frequency \\
\hline Lip & $\begin{array}{l}\text { 1. Place index finger at the corner of the lip } \\
\text { 2. Compress the lip }\end{array}$ & 2 & $\begin{array}{l}\text { Repeat } 4 \text { times, both side, upper } \\
\text { and lower lip }\end{array}$ \\
\hline
\end{tabular}

4. Reverse direction

Lip curl 1. Place thumb and index finger at center of lip

2. Compress the tissue, move finger toward the ear, then down and toward the corner of the lip (i.e., C pattern) 
하였다. 본 연구는 한림대학교 임상시험윤리위원회의 승인(2019-05024)을 받았으며 보호자에게 치료 전 ORT에 관해 충분한 설명을 한 뒤 치료 동의를 얻은 경우 진행하였다.

통계학적 분석은 SPSS version 23.0 (IBM Co., Armonk, NY, USA) 을 이용하였으며 연속변수의 분석은 $t$-test를 이용하였고 비연속변수 의 분석은 카이제곱 검사 혹은 Mann-Whitney 검증을 하였으며, $P$ 값 이 0.05 미만인 경우에 통계적으로 유의하다고 판단하였다.

\section{결과}

\section{1. 대상아의 일반적인 특성}

본 연구 대상아는 총 78명이었으며, ORT를 받은 치료군은 총 39명 이었으며, 치료군을 기준으로 재태 주수와 출생체중을 매칭시킨 대 조군은 39명이었다. 연구 대상아들의 평균 재태 주수는 28.4주였으 며, 평균 출생체중은 치료군은 $1,265.1 \mathrm{~g}$ 이었고, 대조군은 $1,231.8 \mathrm{~g}$ 이었다. 남아의 비율은 두 군 간에 차이가 없었으며, 제왕절개비율

Table 2. Demographics of study populations

\begin{tabular}{lccc}
\hline Variable & ORT (n=39) & Control (n=39) & $P$-value \\
\hline Gestational age (wk) & $28.4 \pm 2.7$ & $28.4 \pm 2.7$ & 1.000 \\
Birth weight (g) & $1,265.1 \pm 432.6$ & $1,231.8 \pm 391.0$ & 0.722 \\
Male sex (\%) & $25(64.1)$ & $20(51.3)$ & 0.252 \\
Cesarean section (\%) & $26(66.7)$ & $27(69.2)$ & 0.808 \\
Apgar score at 1 min & $3.6 \pm 1.5$ & $3.3 \pm 2.0$ & 0.403 \\
Apgar score at 5 min & $5.7 \pm 1.6$ & $5.1 \pm 2.2$ & 0.181 \\
Length of stay (d) & $75.5 \pm 33.3$ & $75.8 \pm 35.4$ & 0.966 \\
PMA at discharge (wk) & $39.0 \pm 2.5$ & $39.1 \pm 2.8$ & 0.866
\end{tabular}

Values are expressed as mean \pm standard deviation or number (\%). Abbreviations: ORT, oral rehabilitation therapy; PMA, postconceptional age.
도 두 군에서 비슷하게 나타났다(Table 2). 출생 초기 1분 및 5분 아프 가 점수모두 두 군 간에 차이가 없었다. 입원 기간은 두 군 모두 평균 76일로 차이가 없었으며, 퇴원 시 PMA 39주로 차이가 없었다. ORT 를 받은 치료군들이 치료 시작 시점의 $\mathrm{PMA}$ 는 평균 $32.1 \pm 1.3$ 주(범위, 32-35)에 시작하였고, 치료 시작 시점의 평균 체중은 $1,608.1 \pm 325.5$ $\mathrm{g}$ (범위, $1,140-2,740$ )이었으며 총 39명의 치료군들이 받은 ORT 기간 은 평균 $28.1 \pm 10.7$ 일간 치료를 받았다.

\section{2. 수유와 관련된 인자들의 비교}

경구수유가 가능한 시작일은 두 군 모두 PMA 33주로 차이가 없었 고 경구수유 시작 후 최소 3 번 이상 연속으로 완전경구수유 가능한 $\mathrm{PMA}$ 는 치료군에서 $33.2 \pm 2.1$ 주, 대조군에서 $34.5 \pm 2.7$ 주로 통계학적 으로 의미 있는 차이는 없었다. 하지만, 완전경구수유 가능한 날의 하 루 총 수유량은 치료군은 평균 $123 \mathrm{~mL}$, 대조군은 $49 \mathrm{~mL}$ 로 치료군의 미숙아들이 훨씬 수유가 잘 진행되는 것을 알 수 있었다 $(P<0.001)$. 또한, 완전경구수유 가능한 날의 평균체중 역시 치료군 $1,82.1 \pm 303.3$ $\mathrm{g}$, 대조군 $1,592.3 \pm 444.1 \mathrm{~g}$ 으로 ORT를 받은 미숙아군이 체중이 더 많 이 나갔다 $(P=0.007)$. 처음 완전경구수유 가능한 날로부터 체중 당 최 소 $150 \mathrm{~mL}$ 먹는 완전장관 영양공급까지 걸린 기간은 치료군에 $15.4 \pm$ 1.4 일, 대조군에서 $23.1 \pm 1.8$ 일로 치료를 받은 미숙아들이 훨씬 빨리 완전장관 영양공급이 가능했다 $(P=0.004)$. 퇴원 시 체중은 치료군은 평균 $3,103 \mathrm{~g}$, 대조군은 $2,744 \mathrm{~g}$ 으로 비슷한 PMA에 퇴원을 하였으나 치료군에서 훨씬 체중이 많이 나갔다 $(P=0.008)$ (Table 3$)$

\section{3. 미숙아관련 합병증의 발생 빈도}

미숙아가 입원 중 겪게 되는 합병증 중 기관지폐형성이상, 미숙아 망막증, 뇌실내출혈, 및 뇌백질연화증 모두 두 군 간 발생 빈도에 차 이가 없었으나, 후기 패혈증의 빈도는 치료군에서는 $12.8 \%$, 대조군 에서는 $25.6 \%$ 로 치료군에서 발생 빈도가 통계학적으로 의미 있게 적

Table 3. Comparison of Outcomes of Variables Related to Feeding

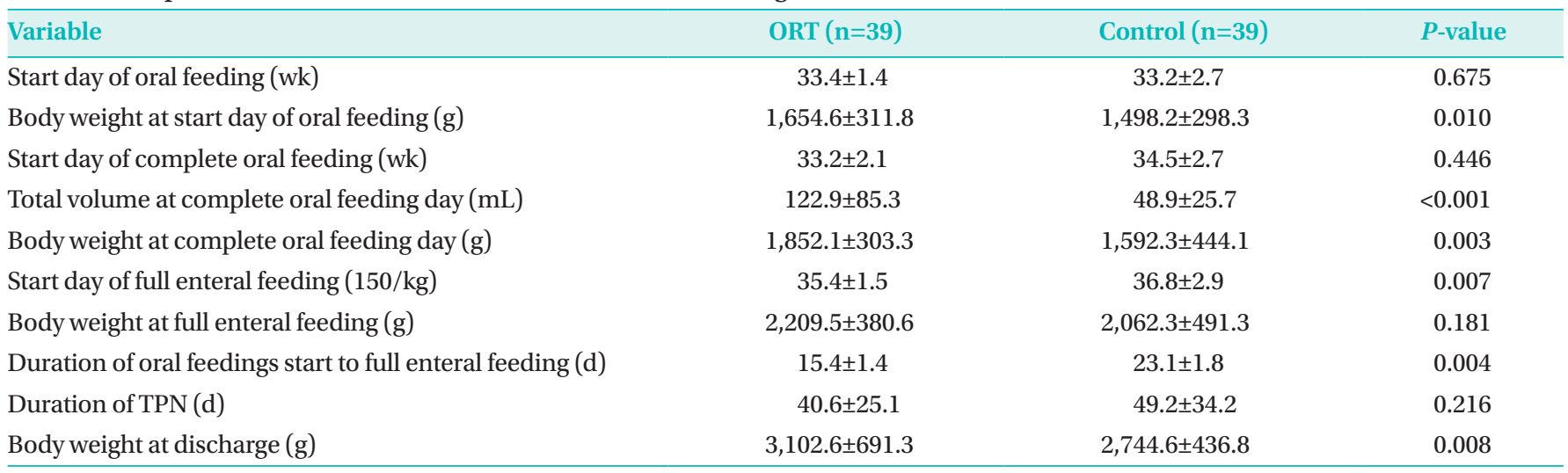

Values are expressed as mean \pm standard deviation.

Abbreviations: ORT, oral rehabilitation therapy; TPN, total parenteral nutrition. 
Table 4. Comparison of Neonatal Major Morbidities

\begin{tabular}{lccc}
\hline Variable & ORT (n=39) & Control (n=39) & $P$-value \\
\hline BPD & $18(46.2)$ & $20(51.3)$ & 0.651 \\
Moderate-to-severe BPD & $10(25.6)$ & $16(41.0)$ & 0.150 \\
ROP with laser treatment & $7(17.9)$ & $10(25.6)$ & 0.584 \\
Late-onset sepsis & $5(12.8)$ & $10(25.6)$ & 0.033 \\
IVH (grade $\geq 3)$ & $1(2.6)$ & $3(7.7)$ & 0.358 \\
PVL & $2(5.1)$ & $3(7.7)$ & 1.000
\end{tabular}

Values are expressed as number (\%).

Abbreviations: ORT, oral rehabilitation therapy; BPD, bronchopulmonary dysplasia; ROP, retinopathy of prematurity; IVH, interventricular hemorrhage; PVL, periventricular leukomalacia.

게 발생했다 $(P=0.033)$ (Table 4).

고찰

본 연구는 NICU에 입원한 고위험 신생아들에게 ORT를 시행한 뒤 그 효과를 보고자 하였고, 연구결과 구강재활치료를 받은 미숙아들 이 그렇지 않은 미숙아들에 비해 경구수유시작은 동일하였지만, 완 전경구수유가 가능할 때 수유량이 치료받은 군에서 훨씬 더 많았고, 완전장관 영양에 도달하는 시기도 약 1 주일 정도 빨랐으며, 그 결과 퇴원 시 체중 역시 치료받은 군에서 훨씬 더 많이 나가는 것을 알 수 있었다.

신생아의 경우 28 주에서 31 주 사이에 자궁 내에서 엄지손가락을 빠는 구강운동이 시작되며, 32 주에서 36 주가 되면 빨기와 숨쉬기의 조정이 이루어진다. 따라서 일찍 태어난 미숙아의 경우 이러한 발 달단계가 충분히 준비되지 않은 상태에서 출생을 하게 되므로 34 주 미만에 태어난 미숙아들은 경구수유 시 더 많은 어려움을 겪을 수 있다 ${ }^{15)}$.

본 연구에서 처음 경구수유의 시작은 두 군 모두 평균 33 주에 시작 가능했고, 이후 최소 3 회 이상 연속으로 경구수유가 가능한 완전경구 수유는 치료군은 33.2 주, 대조군은 34.5 주였다. 이는 본원의 ORT 대 상아가 우선 최소한 32 주가 되어야 치료를 시작했고 발달단계를 고 려해보면 통상적으로 경구수유가 가능한 연령인 34 주보다 빠르다 고 생각되며 32 주 미만의 미숙아들을 대상으로 진행한 연구인 Kim과 $\mathrm{Bang}^{16)}$ 의 결과인 치료군은 재태 주수 33.6주, 대조군 34.3주와 비슷 한 결과를 보였다.

완전경구수유가 가능한 경우 하루 동안 먹은 총 수유량은 치료군 에서 평균 $123 \mathrm{~mL}$, 대조군에서 평균 $49 \mathrm{~mL}$ 로 치료군에서 훨씬 더 많 이 먹는 것을 알 수 있었는데, 이는 구강자극 재활치료를 통해 미숙아 들이 수유를 훨씬 원활하게 할 수 있었던 것으로 생각된다. 이는 결과 적으로 빠른 체중 증가를 보여줬는데 완전경구수유 시 치료군의 평
균 체중은 $1,850 \mathrm{~g}$ 이었고, 대조군은 평균 $1,590 \mathrm{~g}$ 으로 통계학적으로 유의한 차이를 보였다. 또한, 비경구영양공급 없이 경구로만 수유 가 능하며 하루 총 수유량이 체중당 $150 \mathrm{~mL}$ 이상 공급 가능한 완전장관 영양공급이 가능한 재태 주수가 치료군은 평균 35.4 주, 대조군은 평 균 36.8주로 치료군에서 더 빨리 가능했으며, 첫 경구수유 가능일로 부터 완전장관영양공급으로 이행되는 평균기간도 치료군이 15.4 일, 대조군이 23.1일로 약 8 일 정도 빨랐다. 이는 본원에서 시행한 ORT 프로그램이 NICU에 입원한 미숙아들에게 긍정적인 작용을 하고 효 과적으로 수유가 가능하게 됐다는 것을 의미한다고 하겠다.

미숙아들은 경구수유 시 빨기-연화-호흡의 부조화와 입 주변 근육 의 미성숙 및 자극에 대한 과민성 및 부정적 반등 등으로 인해 경관수 유에서 젖병수유로의 이행에 어려움을 겪게 되고 이는 불충분한 체 증 증가 등을 초래하게 되며 결과적으로 입원 기간이 길어지게 하는 원인이 된다고 알려져 있다 ${ }^{3,17,18)}$. 따라서, 일반적으로 미숙아에서 퇴 원을 지연시키는 이유 중 하나인 수유이행의 어려움을 효과적으로 해결하면 입원 기간의 단축이 가능하다고 할 수 있다 ${ }^{5}$. 본 연구에서 는 두 군 간에 평균 입원 기간은 76 일이었고 퇴원 시 평균 재태 주수 도 39 주로 의미 있는 차이는 없었으며, 이는 Fucil 등 ${ }^{14}$ 의 연구결과와 동일하게 구강자극요법이 경구수유로의 이행을 돕지만, 입원 기간을 단축시키지는 않는다는 결과와 일치한다. 본원의 경우 퇴원 기준이 체중 증가 외에 재태 주수도 고려하여 퇴원을 시키게 되므로 두 군 간 에 비슷한 주수에 퇴원하는 결과가 나왔을 것으로 생각된다.

퇴원 시 체중은 치료군에서 평균 $3,103 \mathrm{~g}$ 이었고, 대조군은 $2,745 \mathrm{~g}$ 으로 치료군에서 체중 증가가 훨씬 좋았다. 이는 본원에서 시행한 ORT를 통해 빠른 완전경관수유가 가능해지고 그 결과 퇴원 시 체중 이 더 많이 증가한 것이라고 볼 수 있겠다.

본 연구결과에서 흥미로운 점은 NICU 입원 기간 중 미숙아들이 하 나 이상 겪게 되는 미숙아 관련 합병증의 발생이 기관지폐형성이상, 미숙아 망막증, 뇌실내출혈 및 백질연화증 등에는 두 군 간에 차이가 없었으나, 후기 패혈증은 ORT군에서 13\% 발생한 반면, 대조군에서 는 $26 \%$ 발생했다는 것이다. 이는 경구수유 시작 후 빠른 체중 증가가 가능하게 됨으로써 정맥주사 및 경관수유 등의 비경구수유의 필요성 이 적게 됨으로써 발생률이 줄었을 거라 생각된다.

한편, 이러한 수유 관련 지표들의 향상뿐만 아니라 ORT 시 전담치 료사가 치료하면서 매일매일의 변화를 인지하게 됨으로써 빠는 힘의 증가 및 호흡과의 조화를 평가하게 되고 이에 따라 중재 횟수를 조절 하게 되고 의료진에게 미숙아 각각의 개별적인 경구수유관련 특성을 알려줌으로써 이후 수유를 진행할 때 도움이 되었다. 또한, 보호자에 게도 알려줌으로써 만족도를 높이게 되어 더욱 적극적으로 수유 연 습에 참여하게 되는 긍정적인 효과도 보였다.

본 연구의 한계점으로는 치료대상아가 적어 본 연구결과를 일반 화하기에는 더 많은 연구대상아가 필요하다는 점과 우리나라 실정에 맞는 치료효과를 판정하는 객관적인 지표가 아직은 없다는 점이라고 
하겠다. 또한, 미숙아분유와 모유수유에 따른 수유 진행에 차이를 보 일 수 있지만,실제로는 미숙아분유와 모유를 혼합하여 수유하는 경 우가 많아 수유 종류에 따른 직접적인 차이를 비교하지 못했다는 점 이다. 하지만, 최근 들어 우리나라 신생아학의 발달로 인해 미숙아의 생존율이 높아져 더 작고 더 어린 초극소미숙아들의 발달평가가 중 요해지고 있으므로 ORT의 긍정적인 효과를 보여준 본 연구결과는 의미가 있다고 하겠다. 또한, Choi 등 ${ }^{13)}$ 의 연구에서 제시한 바와 같이 전담치료사뿐만 아니라 퇴원 후에도 보호자가 비교적 쉽게 시행할 수 있는 치료법이므로 NICU에서 퇴원 이후에도 지속적으로 한다면 훨씬 더 긍정적인 효과를 가져올 것이라 생각된다.

결론적으로 NICU에 입원한 고위험 신생아에서 ORT는 경구영양 시작 후 완전장관영양까지 이르는 기간을 단축시켰을 뿐만 아니라, 현저한 체중 증가도 보였으며, 후기 패혈증의 빈도가 감소하는 효과 까지 나타냈다. 본 연구진들은 향후 연구 대상아들을 지속적으로 추 적 관찰하여 모유 혹은 분유수유 이후 이유식으로의 이행 시 및 이후 식이습관 및 성장 관련 추적 관찰을 지속하는 장기적인 효과에 대한 연구를 계획하고 있다.

\section{이해관계}

본 저자는 이 논문과 관련된 이해관계가 없음.

\section{REFERENCES}

1. Kim KS, Bae CW. Trends in survival rate for very low birth weight infants and extremely low birth weight infants in Korea, 1967-2007. Korean J Pediatr 2008;51:237-42.

2. National Institute of Health. Korean Neonatal Network Annual Report 2015. Cheongju: National Institute of Health, 2015.

3. Bingham PM. Deprivation and dysphagia in premature infants J Child Neurol 2009;24:743-9.

4. Barlow SM, Finan DS, Lee J, Chu S. Synthetic orocutaneous stimulation entrains preterm infants with feeding difficulties to suck. J Perinatol 2008;28:541-8.

5. Einarsson-Backes LM, Deitz J, Price R, Glass R, Hays R. The effect of oral support on sucking efficiency in preterm infants. Am J Occup Ther 1994;48:490-8.
6. Field T, Ignatoff E, Stringer S, Brennan J, Greenberg R, Widmayer S, et al. Nonnutritive sucking during tube feedings: effects on preterm neonates in an intensive care unit. Pediatrics 1982; 70:381-4.

7. Leonard EL, Trykowski LE, Kirkpatrick BV. Nutritive sucking in high-risk neonates after perioral stimulation. Phys Ther 1980;60:299-302.

8. Boiron M, Da Nobrega L, Roux S, Henrot A, Saliba E. Effects of oral stimulation and oral support on non-nutritive sucking and feeding performance in preterm infants. Dev Med Child Neurol. 2007;49:439-44.

9. Bragelien R, Rokke W, Markestad T. Stimulation of sucking and swallowing to promote oral feeding in premature infants. Acta Paediatr 2007;96:1430-2.

10. Cunha M, Barreiros J, Goncalves I, Figueiredo H. Nutritive sucking pattern: from very low birth weight preterm to term newborn. Early Hum Dev 2009;85:125-30.

11. Daley HK, Kennedy CM. Meta analysis: effects of interventions on premature infants feeding. J Perinat Neonatal Nurs 2000;14: 62-77.

12. Poore M, Zimmerman E, Barlow SM, Wang J, Gu F. Patterned orocutaneous therapy improves sucking and oral feeding in preterm infants. Acta Paediatr 2008;97:920-7.

13. Choi HW, Park HW, Kim HY, Lim G, Koo SE, Lee BS, et al. Feeding desaturation and effects of orocutaneous stimulation in extremely low birth weight infants. J Korean Soc Neonatol 2010;17:193-200.

14. Fucile S, Gisel E, Lau C. Oral stimulation accelerates the transition from tube to oral feeding in preterm infants. J Pediatr 2002;141:230-6.

15. Rocha AD, Moreira ME, Pimenta HP, Ramos JR, Lucena SL. A randomized study of the efficacy of sensory-motor-oral stimulation and non-nutritive sucking in very low birthweight infant. Early Hum Dev 2007;83:385-8.

16. Kim H, Bang KS. Effects of an oral stimulation program on the transition from tube to bottle feeding in premature infants. J Korean Acad Fundam Nurs 2011;18:160-7.

17. Gaebler CP, Hanzlik JR. The effects of a prefeeding stimulation program on preterm infants. Am J Occup Ther 1996;50:184-92.

18. American Academy of Pediatrics. Committee on Fetus and Newborn. Hospital discharge of the high-risk neonate: proposed guidelines. Pediatrics 1998;102:411-7. 